\title{
Study on the Reform of Table Tennis Teaching Content and Methods in University \\ Chao Wang ${ }^{1, \text { a }}$ \\ ${ }^{1}$ Xijing University, Xi'an, 710123 \\ a email
}

Keywords: Table Tennis, Teaching Content and Its Methods, Reform

\begin{abstract}
Since the basic table tennis technique to learn, easy to master the rules of the game, and the facilities and equipment is simple, economical, indoor and outdoor can be carried out, the amount of exercise vary for different age, sex and physical condition of the participants. Therefore, college sports become a popular elective course options. However, as the table tennis in the university continues to heat up, the corresponding there have been some problems. Therefore, based on College Tennis lessons teachers and college students as subjects, the basic situation of table tennis classes at colleges and universities to carry out an investigation to reveal table tennis teaching deficiencies, on this basis, identify problems, and propose appropriate measures to promote table tennis in the future to further improve teaching in universities and improve sports as a carrier, to improve the teaching quality of contemporary college students.
\end{abstract}

\section{Introduction}

Table tennis originated in the late 19th century England, popular in Europe, the first to be known as the "Table tennis". Since table tennis changing, interest is strong, less demanding of venues and facilities, without restrictions of age, gender and physical aspects, it has carried out better. Often participate in table tennis exercise can improve the body's sensitivity and reaction speed, enhance physical coordination, improve the function of the muscular system, it can also train students good psychological quality, to develop students' mental activity, the formation of good will have a good role. Table Tennis underlying technology to learn, easy to master the rules of the game, and simple facilities and equipment, economy, indoor and outdoor can be carried out, the amount of exercise can be very flexible, suitable for different levels of people to participate in sports. Moreover, the sport has been one of the predominant sports events, known as our country's "national sport." In recent decades, China's table tennis has been a world leader in competitive sports has also made brilliant achievements.

\section{Ping-Pong Common Practice in University Teaching Characteristics}

Features table tennis ball is small, fast, changing, interesting, relatively simple devices, limited by age, sex and physical condition, with wide adaptability and high value of exercise, it is easier to carry out and universal. Table tennis in the indoor and outdoor can be carried out, exercise control, and can easily be accepted by the public. Table tennis with a single, doubles, group projects, group projects through the organization to achieve, so often take part in table tennis can not only exercise agility and coordination, improve the body of the function, also can develop independent thinking, individual and collective combat spirit.

Elective Courses in University Table Tennis (basic class) students, in addition to the usual few before or college table tennis outside contact, most foundation is weak, the technical level is starting from the grip began to teach. However, we can easily see the teaching, students' enrollment, learning high enthusiasm, motivation to learn is also very strong. At the same time, the students also showed a lack of persistent patience, eager to show common. 


\section{Colleges Table Tennis Teaching Problems}

Currently, there is a teacher in Hunan problems are: (1) title unreasonable proportion, fewer teachers senior titles. (2) an unreasonable level of education, the lower the proportion of highly educated teachers. (3) low proportion of professional tennis teachers. 67.9 percent of Ping Pong Optional Course teachers are transferred over from other special classes to teach table tennis, as well as $48.6 \%$ of the teachers to work since table tennis was not always engaged in teaching work. (4) teacher-student ratio is irrational, excessive number of students in classroom teaching. Opportunities (5) teachers to participate in education and training is too small, thus seriously affecting the quality of teaching in Hunan Province ordinary university Pingpong elective classes, limiting its better development.

Elective Courses are students according to their interests elective from the present situation of college overall Hunan Province, the majority of students in table tennis has a strong interest in, and want to learn table tennis, as college enrollment for the various provinces and cities students from all over the world, suffered sports school environment, family conditions, the college entrance examination system, different basic physical fitness and activity level and other factors, resulting in a gap between the level of table tennis, a tennis class options are there generally high , the difference, the difference of technical level [74]. Moreover, the differences in teaching a class of students' personality is an objective reality, and this must be recognized that there are sensible form, will type the emotional type of character; there are high and low ability. In conclusion, the student's personality characteristics are vastly different. Colleges and universities table tennis elective course content is to teach students basic knowledge of sports, technology and basic skills in teaching in general. It contains a table tennis table tennis training as well as basic knowledge of two categories, according to the sports curriculum and textbook requirements, it has a broad, scientific and systematic. In one class, students are substantially normal levels, so that the teaching content should meet most students' level, and long-term courses in University Table Tennis affected sports, exam-oriented education, most teachers only in accordance with the unified arrangement of teaching syllabus content and teaching schedule, physical activity and exercise intensity arrangement is not reasonable, resulting in some students have enough to eat, they can not digest some of the situation, the impact of their teaching. From the current teaching content himself investigation of General Colleges and table tennis elective point of view, its general features are: presence to teach special skills and tactics based teaching mode in teaching work, the larger the proportion; the theoretical part, the proportion of teaching and assessment skills portion of the small part, the teaching content is not reasonable; hours between universities gap was large, non-uniform distribution of hours and so on.

In the education system for many years, teaching mode is based on teachers' organizations in the form of the center, over the years has been extended four sports classroom style of teaching programs, namely the beginning, ready to part, the basic part of the end portion, or three-stage teaching program, which began with the preparation part, the basic part of the end part, for decades the basic procedures fixed. Currently, the class table tennis elective Hunan colleges and universities, teachers focus only on teaching techniques and improve movement carved explore movement technology, a "one size fits all" in the classroom teaching, the "march" form of teaching, ignored the students' personal interests, hobbies, develop expertise, repressed personality development of students, ignoring the main role of students, too much emphasis on the leading role of teachers, leading table tennis teaching stylized, rigid teaching methods, students are not interested in the classroom, It is not conducive to teachers teaching. Some teachers Despite the use of modern educational technology aspirations, but by their level of education and conditions of hardware limitations, and restrictions subjective and objective conditions, less use of modern educational technology, it will affect the effectiveness of teaching tennis lessons, but also limits the the cultivation of students' initiative. As a result, not to stimulate the enthusiasm of students, eager to learn and even has been ruthlessly extinguished, seriously affecting the quality of classroom teaching. 
"Stadiums conditions are a major influence in University Table Tennis Teaching." In modern society, the most important issue facing the development of sports is the economy, too, is the economic problems of the College Stadiums will encounter. Economic restructuring impact college sports venues industry, but difficult to meet the College funds invested in the construction and maintenance of sports facilities, the level of investment compared to the College Sports Facilities with the developed countries, is still at a low level. College Stadiums lack of resources in the performance of the main reasons: First, due to lack of funding college sports, which is used to put into the construction of venues and facilities also less, with obsolete equipment, aging, resulting in the venue and the number of college students have at present disproportion. Inadequate investment in venue construction is a serious impact on daily physical education for college and for the public health service.

\section{College Table Tennis Teaching Strategies}

Strong faculty is an important factor in the impact of the development of table tennis elective classes, greatly improve the quality of $\mathrm{PE}$ teachers is an important aspect of improving the quality of teachers. Professional quality and ability of teachers can be reinforced from the following aspects: For some high level of expertise of teachers should begin their theoretical knowledge, to more experienced old teachers to learn and to ask, and actively improve their classroom teaching ability, so students learn the necessary knowledge; and for those who have certain qualifications and PE teachers titles, it should improve its own business level and actively practice, improve their professional skills, doing demonstration action, giving students the perfect action sense, to stimulate student interest in learning.

Physical education content is based on the selected target sports teaching, and teaching conditions required for processing in accordance with the development of students in sports teaching and learning environment to teach students the principles of sports knowledge sports technology and competition methods. Therefore, the quality of teaching content is directly related to the level of quality in University Table Tennis Teaching. In teaching some practical proof: the choice of teaching content should have some practical value, the difficulty should be moderate, so that students through their own efforts to understand and some completed, this will make learning a certain sense of pride and satisfaction that which had a strong interest in learning table tennis.

Based on the investigation to know the current College of theory teaching part of table tennis elective course quite seriously, and even some teachers said that the theory course content to fit Practice Course to talk directly. "National Teaching Guidelines for PE Course Colleges" clearly states: school sports should use modern teaching methods and forms, arrange some theoretical teaching content improves the level of theoretical knowledge of students. And because the effectiveness of students' sports practice, long-term need for the theory of knowledge as a guide, so teachers should strengthen the theory course content attention and reform. In particular: to appropriately increase the table tennis competition rules and simple techniques and tactics of the class lesson in theory, to explain the table tennis competition of knowledge, we should explain the difficulty and depth of its content according to the actual situation of the students. So that students fully understand and master the knowledge of sports competition rules. Then according to teachers on content, play the initiative of students allowed to talk about their ideas, so that students get pleasure from the discussion of all kinds of knowledge of table tennis, acquire knowledge. Teachers may also be in the organization, the use of multimedia equipment for students to watch the high-level ping-pong tournament, ping-pong allow them to enjoy the charm of movement, to increase students' interest and motivation to facilitate student table tennis theoretical knowledge of progress and improvement.

Stadiums are to improve the level of competitive sports and fitness activities were indispensable hardware facilities, but also the development of an important carrier of the sports industry. Venues and facilities is to ensure that colleges and universities table tennis physical education, extracurricular sports activities and after-school sports training, sports competitions normally essential material conditions, is the implementation of "health first" guiding ideology of the carrier, 
is organic basic school teaching conditions part, to enrich students' campus life and promote the physical and mental development of students. If the facility is not enough space, well, that Universities Table Tennis is just empty talk, not to implement the practice. Problems venues and facilities reflect the bottleneck of Table Tennis in Colleges. It has become a major obstacle in University Table Tennis undertaken.

Extra-curricular activities are a student activities outside the classroom, school extracurricular educational activities in an extension. Its main purpose is to develop students 'interest, can promote the normal development of the student body, enhance physical fitness of students, students lay the foundation for lifelong physical, and spiritual civilization construction of campus, students develop expertise and broaden students' knowledge, more efficient use of extracurricular time to conduct table tennis. Therefore, in order to enrich Hunan university student table tennis extracurricular activities, the school should be organized and planned manner each semester on a regular basis to carry out some tennis clubs and tennis association activities, such as: Table Tennis Association classes, so that students have more opportunity to participate in extracurricular activities table tennis, so that we learn from each other progress in order to build a sound management system to run, so that colleges and universities in Hunan Province Table tennis rapid, vigorous development.

Extracurricular sports competition is that students in their spare time to participate in extracurricular cultural and sports life to enrich and enhance the physical fitness of students in sports. In modern society, sports charm and attraction arises from the competition can stimulate the potential of students enhance the sense of pride, extracurricular table tennis game is a good way to attract students. However, according to the survey, most of the table tennis competition conducted by the Hunan College cases are student organizations, extracurricular activities is difficult to play an active role in promoting table tennis to carry on. So hold some interesting exchanges games, such as: the school table tennis tournament was held, the Ministry of faculties selection, which led to the selection of all grades, develop inter-related, and promote the development of table tennis in college better.

\section{Conclusion}

The era of progress of social development, physical education must be reformed. The essence of reform is the trend of the times, the courage to abandon old ideas, the courage to accept new things, new ideas, giving sports teaching with renewed vigor and flavor of the times. Therefore, we want to reform as an opportunity to the specific circumstances and characteristics of the school as the focus of teaching materials, teaching methods reform, to explore their own teaching materials and teaching methods compose, and bold in practice, it is the trend of our times.

\section{References}

[1] Huang Pingbo. The College Sports Facilities Market Analysis [J]. Physical Culture Guide, 2008, (8): 96-99.

[2] Huo Jianxin, Li Fu. Utilization Chinese Universities Stadiums [J]. Tianjin Institute of Physical Education, 2007, 22 (2): 179-181.

[3] Zhu Wei, Li Hongqiang. Investigation on Beijing college students in extracurricular sports activities and mental health [J]. Xi'an Institute of Physical Education, 2008, (5): 127-130.

[4] Ji Hongying. understand the use of Teaching in Table Tennis Teaching [J] Journal of Changzhou Institute of Information Technology, 2004, (6): 47-48.

[5] Wang Jieyang, Chang Linfan, Dong Sen, Wang Qilu. Experimental study on improving student table tennis vision [J]. Hubei Sports Science, 1998, (4): 95-96.

[6] YangPeiji, Zhou Xuebing, Yu Xiaodong. Study college students' extracurricular sports activities of some regions of China [J]. Beijing Sports University, 2009, (6): 91-93. 